\title{
Non-invasive ventilation for acute exacerbations of COPD: a new standard of care
}

\author{
Laurent Brochard
}

Acute exacerbations of chronic obstructive pulmonary disease (COPD) are a frequent cause of admission to hospital and the intensive care unit (ICU). During these episodes a major deterioration in gas exchange is accompanied by a worsening in the clinical condition of the patient, characterised by a rapid and shallow breathing pattern, severe dyspnoea, right ventricular failure, and encephalopathy. The pathophysiological pathway of all these features is the inability of the respiratory system to maintain adequate alveolar ventilation in the presence of major abnormalities in respiratory mechanics. Hypercapnia, acidosis, and hypoxaemia all ensue, leading to clinical deterioration in cardiovascular and neurological functions. What triggers the abnormal breathing pattern of the patient is still unclear. Although it has been suggested that rapid shallow breathing may afford a protection against the development of respiratory muscle fatigue, this notion has been challenged by studies of weaning off mechanical ventilation where the occurrence of acute respiratory failure can be closely monitored and analysed. ${ }^{12}$ The key element during decompensation seems to be the shortening of the inspiratory time, inducing both a decrease in tidal volume and an increase in respiratory frequency. Because this is associated with, or is secondary to, excessive respiratory loads, treatment should be directed at reducing the loads imposed on the respiratory muscles. Unfortunately, the ability of medical treatment to reverse severe respiratory failure in these patients is limited. When hypoventilation becomes so severe that several organ dysfunctions occur, there is no choice other than to provide "artificial" ventilation to avoid a fatal outcome. The traditional way has been to use endotracheal intubation as a means of access to the lower airways and to deliver ventilation to the patient's lungs. A more recent approach, called non-invasive ventilation (NIV), has profoundly changed the management and outcome of these patients. ${ }^{34}$

Three important characteristics of NIV in this setting are worth mentioning. The first one concerns ventilation itself. The success of the technique is based on the ability of assisted ventilation (or synchronised ventilation) to improve alveolar ventilation by increasing tidal volume. The widely accepted pressure targeted modes deliver support in synchrony with the patient's inspiratory effort, which usually results in an increase in tidal volume, subsequently associated with a reduction in the amount of effort performed by the patient. ${ }^{5}$ The ability of these modes to improve the volume delivered to the lung explains the ability of NIV to reverse other clinical and gas exchange abnormalities. ${ }^{67}$ The second characteristic of NIV is that it is an intermittent mode of support. NIV is usually delivered for only a few hours during a 24 hour period (usually 6-12 hours) and is very rarely delivered as a continuous support. Indeed, despite the presence of severe hypoventilation, these patients can be managed without fully replacing the respiratory system function, as is the case during anaesthesia or central nervous system disorders. These patients have a highly stimulated and active respiratory drive and can therefore sustain prolonged periods of spontaneous breathing. However, the treatment should provide a reduction in the amount of effort needed and intermittent support seems to be adequate. When the need for ventilatory support becomes permanent, tolerance of the mask becomes a limitation and is frequently a cause of failure. The third characteristic of NIV is the use of a face mask in place of an endotracheal tube. Although the use of these masks is associated with specific problems such as leaks and limited clinical tolerance, they have been shown to replace endotracheal intubation advantageously as a first line treatment.

In a large randomised controlled trial comparing NIV with a standard ICU approach where endotracheal intubation was performed after failure of medical treatment, the use of NIV was shown to reduce complications, length of stay in the ICU, and mortality. ${ }^{4}$ In patients in whom endotracheal intubation was performed, the in-hospital mortality rate was nearly $30 \%$ which was similar to the $25 \%$ of NIV patients who eventually required endotracheal intubation. However, because the number of patients requiring endotracheal intubation was much smaller with the NIV approach, the overall mortality was reduced to less than $10 \%$ in patients receiving NIV.

In a study performed by Bott and coworkers a reduction in mortality was suggested when treatment with NIV was compared with medical treatment alone, but only a few patients received endotracheal intubation after failure of the medical treatment. ${ }^{3}$ Plant and colleagues recently published the largest study to date on the use of NIV for acute respiratory failure in patients with COPD. ${ }^{8}$ This important study was a prospective, multicentre, randomised trial in which NIV was compared with standard treatment in patients with mild to moderate respiratory acidosis. NIV was administered on the ward with a median nurse to patient ratio of $1 / 11$, ranging from $1 / 26$ to $1 / 13$. Formal training in NIV was delivered in every centre for $7-8$ hours during the preceding three months, plus one additional hour each month to maintain the skills. Of the 236 patients enrolled, half were given medical treatment and half received NIV. Based on a priori failure criteria, the analysis showed that significantly more patients failed in the control group $(27 \%$ versus $15 \%)$. The presence of these failure criteria did not always lead to endotracheal intubation. The in-hospital mortality, however, was also significantly reduced by NIV from $20 \%(29 / 118)$ to $10 \%(12 / 118)$. The investigators also found that $\mathrm{pH}$, respiratory rate, and breathlessness were more rapidly improved with NIV. In a post hoc analysis the authors found that, in patients with an initial $\mathrm{pH}$ of $\geqslant 7.30, \mathrm{NIV}$ was very effective in reducing the rate of failure. For patients with $\mathrm{pH}$ of $<7.30$ on admission only a trend existed for the effect of NIV on mortality. It should be noted that, in this subgroup, the mortality rate remained relatively high compared with mortality figures for COPD given in the literature.

One could summarise all these studies by saying that NIV has been shown to offer better outcomes to patients admitted with acute exacerbations of COPD than either medical treatment alone or ICU management with endotracheal intubation as second line treatment (approximately $75 \%$ of patients). Three complementary interventions can therefore now be proposed in a stepwise approach to these patients, and their combination should become a 
new standard of care. The first step is based on drug treatment and on appropriate management of oxygen. ${ }^{9}$ Although more data are now available in this field, research directed at optimising drug treatment and establishing the optimal target for oxygen therapy are needed. The second step is the early use of NIV to prevent further worsening and clinical deterioration. How soon this treatment should be applied is still a matter of debate and may be difficult to base solely on objectively quantified criteria. The data by Plant et al, however, offer very strong arguments for delivering NIV as soon as the patient develops moderate respiratory acidosis with a $\mathrm{pH}$ of $\leqslant 7.35$ and increased $\mathrm{PaCO}_{2}$. The early use of NIV had been challenged by the results of negative studies which found no effect of NIV in patients who did not require endotracheal intubation and none of whom died. ${ }^{10}$ The study by Plant et al, however, is the only one with sufficient power to address the benefits of NIV in patients with a low mortality rate. In addition, three Italian cohort studies with historical or matched controlled groups have suggested that the long term outcome of patients treated with NIV may be much better than that of patients treated with medical therapy and/or with endotracheal intubation. ${ }^{11-13}$ The final treatment step is therefore endotracheal intubation and mechanical ventilation. This should be reserved for patients in whom NIV is contraindicated, for those meeting intubation criteria despite NIV, or those requiring immediate endotracheal intubation on admission. The management of mechanically ventilated patients with COPD has been made much easier over the last 10-15 years by a better understanding and management of weaning ${ }^{14-16}$ and by the use of NIV to shorten the duration of invasive ventilation. ${ }^{17} 18$ Better management of sedation will also help to reduce the duration of mechanical ventilation. ${ }^{19}$ The overall mortality rate of mechanically ventilated patients with COPD is usually much lower than for other ICU diseases such as the acute respiratory distress syndrome or septic shock, and the length of mechanical ventilation is not much longer than for other ventilated patients. These three treatment steps may therefore become the new standard for management of patients with acute exacerbations of COPD.

Is NIV an easy technique to apply in the ward? Wherever it is delivered, specific training is necessary for its optimal administration, as emphasised by Plant and colleagues. This is true both in the medical ward, in the emergency department, and in the ICU. Indeed, a specific approach is required to optimise the ventilation delivered, to decrease leaks, and to help the patient to understand, accept, and tolerate the technique. The sooner NIV is applied, the easier it is. More severe patients may require more careful and continuous monitoring which can be provided in more specialised centres. There is no unique solution, however, for the optimal delivery of care, including NIV, to patients with COPD. Local organisation also depends on resources and availability of beds. Because, on the one hand, the long term outcome of patients with COPD remains poor and, on the other, a new approach is now available to improve the short term outcome in these patients, we should make every effort to develop and promote this three step approach which, hopefully, will also improve their long term outcome.

LAURENT BROCHARD

Medical Intensive Care Unit,

Henri Mondor Hospital, AP-HP,

University Paris 12,

F-94010 Créteil, France

email :laurent.brochard@hmn.ap-hop-paris.fr

1 Tobin MJ, Perez W, Guenther SM, et al. The pattern of breathing during successful and unsucessful trials of weaning from mechanical ventilation. Am Rev Respir Dis 1986;134:1111-8.

2 Jubran A, Tobin MJ. Pathophysiologic basis of acute respiratory distress in patients who fail a trial of weaning from mechanical ventilation. Am f Respir Crit Care Med 1997;155:906-15.

3 Bott J, Carroll MP, Conway JH, et al. Randomised controlled trial of nasal ventilation in acute ventilatory failure due to chronic obstructive airways disease. Lancet 1993;341:1555-7.

4 Brochard L, Mancebo J, Wysocki M, et al. Noninvasive ventilation for acute exacerbations of chronic obstructive pulmonary disease. $N$ Engl f Med 1995;333:817-22.

5 Brochard L, Isabey D, Piquet J, et al. Reversal of acute exacerbations of chronic obstructive lung disease by inspiratory assistance with a face mask. N Engl f Med 1990;323:1523-30.

6 Thorens JB, Ritz M, Reynard C, et al. Haemodynamic and endocrinological effects of noninvasive mechanical ventilation in respiratory failure. Eur Respir f 1997;10:2553-9.

7 Diaz O, Iglesia R, Ferrer M, et al. Effects of noninvasive ventilation on pulmonary gas exchange and hemodynamics during acute hypercapnic exacerbations of chronic obstructive pulmonary disease. Am $\mathcal{F}$ Respir Crit Care Med 1997;156:1840-5.

8 Plant P, Owen J, Elliott M. A multicentre randomised controlled trial of the early use of non-invasive ventilation for acute exacerbations of chronic obstructive pulmonary disease. Lancet 2000;355:1931-5.

9 Warren PM, Flenley DC, Millar JC, et al. Respiratory failure revisited: acute exacerbations of chronic bronchitis between 1961-1968 and 1970-1976. Lancet 1980;i:467-71.

10 Barbé F, Togores B, Rubi M, et al. Noninvasive ventilatory support does not facilitate recovery from acute respiratory failure in chronic obstructive pulmonary disease. Eur Respir 7 1996;9:1240-5.

11 Vitacca M, Rubini F, Foglio K, et al. Non invasive modalities of positive pressure ventilation improve the outcome of acute exacerbations in COLD patients. Intensive Care Med 1993;19:450-5.

12 Confalonieri M, Parigi P, Scartabellati A, et al. Noninvasive mechanical ventilation improves the immediate and long-terme outcome of COPD patients with acute respiratory failure. Eur Respir F 1996;9:422-30.

13 Bardi G, Pierotello R, Desideri $M$, et al. Nasal ventilation in COPD exacerbations: early and late results of a prospective, controlled study. Eur Respir f 2000;15:98-104.

14 Brochard L, Rauss A, Benito S, et al. Comparison of three methods of gradual withdrawal from ventilatory support during weaning from mechanical ventilation. Am $\mathcal{f}$ Respir Crit Care Med 1994;150:896-903.

15 Esteban A, Frutos F, Tobin MJ, et al. A comparison of four methods of weaning patients from mechanical ventilation. $N$ Engl f Med 1995;332: $345-50$

16 Ely EW, Baker AM, Dunagan DP, et al. Effect on the duration of mechanical ventilation of identifying patients capable of breathing spontaneously. $N$ Engl f Med 1996;335:1864-9.

17 Nava S, Ambrosino N, Clini E, et al. Noninvasive mechanical ventilation in the weaning of patients with respiratory failure due to chronic obstructive pulmonary disease. A randomized, controlled trial. Ann Intern Med 1998;128:721-8.

18 Girault C, Daudenthun I, Chevron V, et al. Noninvasive ventilation as a systematic extubation and weaning technique in acute-on-chronic respiratory failure. Am f Respir Crit Care Med 1999;160:86-92.

19 Kress JP, Pohlman AS, O'Connor MF, et al. Daily interruption of sedative infusions in critically ill patients undergoing mechanical ventilation. New Engl f Med 2000;342:1471-7. 